\title{
Genetic variation in TLR or NFkappaB pathways and the risk of breast cancer: a case-control study
}

\author{
Alexa J Resler ${ }^{1,3,5^{*}}$, Kathleen E Malone ${ }^{1,3}$, Lisa G Johnson ${ }^{1}$, Mari Malkki², Effie W Petersdorf ${ }^{2}$, \\ Barbara McKnight ${ }^{1,4}$ and Margaret M Madeleine ${ }^{1,3}$
}

\begin{abstract}
Background: Toll-like receptors (TLRs) and the transcription factor nuclear factor-kB (NFkB) are important in inflammation and cancer.

Methods: We examined the association between breast cancer risk and 233 tagging single nucleotide polymorphisms within 31 candidate genes involved in TLR or NFKB pathways. This population-based study in the Seattle area included 845 invasive breast cancer cases, diagnosed between 1997 and 1999, and 807 controls aged 65-79.

Results: Variant alleles in four genes were associated with breast cancer risk based on gene-level tests: MAP3K1, MMP9, TANK, and TLR9. These results were similar when the risk of breast cancer was examined within ductal and luminal subtypes. Subsequent exploratory pathway analyses using the GRASS algorithm found no associations for genes in TLR or NFKB pathways. Using publicly available CGEMS GWAS data to validate significant findings ( $N=1,145$ cases, $N=1,142$ controls), rs889312 near MAP3K1 was confirmed to be associated with breast cancer risk $(P=0.04, \mathrm{OR}$ $1.15,95 \% \mathrm{Cl} 1.01-1.30)$. Further, two SNPs in TANK that were significant in our data, rs $17705608(P=0.05)$ and rs 7309 $(P=0.04$ ), had similar risk estimates in the CGEMS data (rs17705608 OR 0.83, 95\% Cl 0.72-0.96; CGEMS OR 0.90, 95\% Cl 0.80-1.01 and rs7309 OR 0.83, 95\% Cl 0.73-0.95; CGEMS OR 0.91, 95\% Cl 0.81-1.02).

Conclusions: Our findings suggest plausible associations between breast cancer risk and genes in TLR or NFKB pathways. Given the few suggestive associations in our data and the compelling biologic rationale for an association between genetic variation in these pathways and breast cancer risk, further studies are warranted that examine these effects.
\end{abstract}

Keywords: Breast cancer, Genetic variation, Inflammation, TLR, NFKB

\section{Background}

Tumor-promoting inflammation has been linked to cancer development in prior research [1-5], and has become recognized as an "enabling characteristic" of other cancer hallmarks such as angiogenesis, cell proliferation and survival, and metastasis [6,7]. The presence of inflammatory messengers in the tumor microenvironment is an important feature of cancer-related inflammation. Many such messengers, including cytokines and chemokines,

\footnotetext{
* Correspondence: aresler@fhcrc.org

${ }^{1}$ Program in Epidemiology, Fred Hutchinson Cancer Research Center, 1100 Fairview Avenue North, Seattle, WA 98109, USA

${ }^{3}$ Department of Epidemiology, University of Washington, Health Sciences Building, NE Pacific Street, Seattle, WA 98195, USA

Full list of author information is available at the end of the article
}

are produced in response to signaling by transcription factors, such as nuclear factor- $\mathrm{kB}(\mathrm{NF \kappa B})[1,3,4]$.

As modulators between inflammation and cancer, $\mathrm{NF \kappa B}$ pathway genes play a central role in innate immunity and acute inflammatory response $[8,9]$. In normal cells, NFKB is activated by various stimuli, such as pathogens and pro-inflammatory cytokines, and controls the expression of multiple target genes, such as $T N F$, IL6, and MMP9 [10-13]. In tumor cells, genetic mutations can compromise NFKB activation, and deregulated expression of genes controlled by $\mathrm{NF \kappa B}$ can affect cell proliferation, apoptosis, and cell migration $[8,14,15]$. Deregulated activation of $\mathrm{NF} \mathrm{B}$ has been seen in many common types of cancer, and previous findings suggest that $\mathrm{NF}_{\mathrm{K} B}$ may be important in breast cancer [16-18].

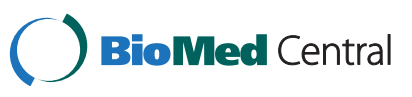


While NFkB-related pathway genes are critical in innate and adaptive immune responses, genes in toll-like receptor (TLR) signaling pathways are also important as they activate $\mathrm{NF}_{\kappa} \mathrm{B}$ in addition to other signaling pathways [19]. In normal epithelial cells and cancer cells, TLRs regulate cell proliferation and survival through triggering MAPK and $\mathrm{NF}_{\kappa} \mathrm{B}$ as well as by mediating the release of cytokines and chemokines [20]. In vitro studies have observed that TLRs are highly expressed in breast cancer cell lines, suggesting that reduced TLR expression could potentially inhibit cell proliferation and survival in breast cancer [21-23].

Further, there is evidence of variants in TLR or NFKBrelated pathways affecting gene function. For example, an insertion/deletion (94ins/delATTG) in the promoter of NFKB1 has been shown to affect transcription [24]. In mice studies, polymorphisms identified in the promoter region, first intron, and 3' untranslated region (UTR) of TNF have been shown to affect production of the cytokine TNF [25]. Likewise, two prior studies found the allele -308A in TNF was associated with elevated TNF expression in vitro $[25,26]$. Additionally, two missense polymorphisms inTLR4, rs4986790 (D299G) and rs4986791 (T399I), have been shown to affect the extracellular domain of the TLR4 receptor [27]. Prior studies such as these suggest that polymorphisms in TLR or NFKBrelated pathways could affect gene function, and therefore may play a role in cancer susceptibility.

This study examined the association between tagging single nucleotide polymorphisms (tagSNPs) within candidate genes in either TLR or NFKB signaling pathways and breast cancer risk in post-menopausal women. We also conducted an exploratory analysis of multiple genes in TLR or NFKB pathways. We focused this study on older women as circulating levels of pro-inflammatory factors increase with age and breast cancer incidence is highest in this age group.

\section{Methods}

\section{Study population}

Participant recruitment has been described previously [28]. Briefly, cases were women aged 65-79 when diagnosed with invasive breast cancer between April 1997 and May 1999 in the three-county Seattle metropolitan area. Cases were ascertained through the Cancer Surveillance System, a population-based cancer registry included in the Surveillance, Epidemiology and End results (SEER) program [29]. Controls were identified from the general population using Health Care Financing Administration records and were assigned reference dates to match the distribution of diagnosis dates for cases. Controls were frequency matched to cases in 5-year age groups. Of the 1,210 and 1,365 eligible cases and controls, 975 (81\%) and 1,007 (74\%) completed in-person interviews. DNA was extracted from blood that was collected from 891 cases and 878 controls at the time of interview. Among these participants, adequate DNA was available for 887 cases and 872 controls. Study protocol was approved by the Fred Hutchinson Cancer Research Center institutional review board and written informed consent was obtained from all study participants.

Information that detailed histology, estrogen receptor (ER) status, and progesterone receptor (PR) status was obtained from the Cancer Surveillance System. Tumors were categorized as luminal (ER or PR positive) or nonluminal (ER and PR negative) subtype. Histology was categorized by ICDO codes as ductal (8500), lobular (8520), ductal/lobular (8522), or other $(8000,8481,8490$, 8501, 8512, 8521, 8530, 8980).

\section{Single nucleotide polymorphism (SNP) selection}

As part of a study of breast cancer and inflammation, we examined 1,536 SNPs in pro- or anti-inflammatory genes. For this study, we selected a total of 233 SNPs from 31 genes in TLR or NFKB signaling pathways. The following genes were included: $A Z I 2$, IFIH1, IKBKE, IRAK4, IRF3, MAP3K1, MAP3K7, MMP9, NFKB1, NFKB2, RELA, RELB, TANK, TBK1, TICAM1, TICAM2, TIRAP, TLR3, TLR4, TLR7, TLR9, TNF, TNFRSF1A, TNFRSF1B, TOLLIP, TRAF3, TRAF6, UBE2C, UBE3A, $V I S A$, and ZBP1. Using the software SNAGGER [30] on publicly available HapMap and SeattleSNPs data, tagSNPs were selected among Caucasians based on an $r^{2}$ value of at least 0.80 and a minor allele frequency (MAF) of 0.05 . The tagSNPs were chosen from regions representing the candidate genes plus 4,000 base pairs both $3^{\prime}$ and $5^{\prime}$ of the gene. SNP selection was prioritized based on functional importance, giving SNPs in coding regions priority over those in other regions. To ensure that at least one SNP from each bin would be successfully genotyped, more than one tagSNP was chosen where a bin included more than 10 SNPs. Additionally, coding SNPs within candidate genes with a MAF of at least 0.02 and also SNPs found to be associated with cancer risk in previous studies were included in the panel. For example, rs889312 in the region surrounding $M A P 3 K 1$ was selected for analysis based on its significance in prior genome-wide association studies (GWAS) [31,32].

\section{Genotyping assay}

Genotyping was performed on 887 cases and 872 controls using the Illumina GoldenGate multiplex platform (N SNPs $=1,536)$. Additional assays were run on the KASPAR platform at KBioscience for SNPs not covered on the Illumina platform or that appeared to be failing on Illumina after an interim review (N SNPs $=102)$. For the current analysis, all 233 SNPs were genotyped on Illumina and four were additionally typed on KASPAR. 
Of these four SNPs, three failed on Illumina and passed on KASPAR (rs7251, rs10025405, and rs1927907) and one was successfully typed on both platforms (rs5746026) that had a cross-platform concordance of $99.7 \%$. We used results from Illumina to analyze rs5746026 as the call rate was $100 \%$. Replicate aliquots were included for $143(8 \%)$ of the 1,759 participants. Of these replicate-pairs, nine had discordant genotypes of at least 1\% among passing SNPs. Monomorphic SNPs or those with call rates less than $90 \%$ were excluded from analysis. All SNPs included in this study had Hardy-Weinberg Equilibrium (HWE) p-values greater than 0.001 among Caucasian controls.

\section{Statistical methods}

To account for potential confounding due to population stratification, we used principal components analysis to restrict our sample to 1,652 white women [33]. Briefly, principal components were computed from 872 controls after standardizing the 1,349 SNPs that passed our quality control checks according to the method outlined by Price et al. [33] The first principal component was sufficient to distinguish white from non-white women. Principal components were computed for the entire sample of 1,759 cases and controls after standardizing the 1,349 SNPs to the control population. We determined clusters of white and non-white subjects using the same restriction criteria from the control population. The final study sample consisted of 1,652 individuals that clustered with white women and self-reported their race as white or Hispanic.

Using these 845 cases and 807 controls, the relative risk of breast cancer associated with each SNP was approximated using logistic regression to compute odds ratios (OR) and 95\% confidence intervals (CI). All models were adjusted for continuous linear age at reference and were log-additive. However, dominant models were fit when genotype cell counts were less than 5 for either cases or controls. We adjusted for multiple comparisons within a gene by using a minP permutation test with 10,000 replications to assess the significance of each gene [34]. For genes found to be significant $(P \leq 0.05)$ based on the minP permutation test, we used logistic regression to examine the association between SNPs and the risk of ductal histology $(\mathrm{N}=565)$ and luminal breast cancer $(\mathrm{N}=744)$ subtype compared to all controls. These models were adjusted for continuous linear age at reference and were log-additive.

The gene set ridge regression in association studies (GRASS) algorithm was used to conduct exploratory pathway analyses for genes in TLR or NFKB pathways [35]. We examined the association between breast cancer risk and two pathways for genes in our dataset by selecting genes from the Kyoto Encyclopedia of Genes and Genomes (KEGG) “Toll-like receptor signaling pathway" (http://www.genome.jp/kegg/pathway/hsa/hsa04620.html). The first pathway included TLR3, TLR4, TLR7, TLR9, TIRAP, TICAM1, TICAM2, TOLLIP, IRAK4, TRAF3, TRAF6, MAP3K7, IRF3, and IKBKE. The second pathway included these genes in addition to NFKB1, $N F K B 2, R E L A$, and RELB. Prior to running any models with GRASS, we imputed any missing SNP values. All imputation was performed using BEAGLE 3.3 with a reference panel of phased genotype data from 283 European individuals sequenced by the 1000 Genomes Project [36]. Pathways were determined as significant based on a permutation test with 10,000 replications.

Finally, we used publicly available data from the Cancer Genetics Markers of Susceptibility (CGEMS) Breast Cancer Genome-Wide Association Scan to validate our significant findings [37]. A Holm multiple test procedure was used to compute permutation corrected p-values with 10,000 replications for individual SNPs within significant genes in our data [38]. For SNPs found to be significant (Holm $P \leq 0.05$ ), the risk of breast cancer associated with each SNP was computed using logistic regression in the CGEMS data, after adjusting for age in 5 -year groups. BEAGLE was used to impute seven SNPs that were not already present within the CGEMS data using phased genotype data from the 1000 Genomes Project as a reference panel. Six SNPs with successful imputation $\left(r^{2}>0.90\right)$ were used for analysis.

All analyses were performed using Stata 11 or $R$ version 2.10.1.

\section{Results}

Cases and controls did not vary substantially in demographic characteristics (Table 1), but there were some key differences for other factors. More cases than controls had a high body mass index (63\% vs. $57 \%$, respectively), and family history of breast cancer was more frequent in cases than controls (60\% vs. 46\%). Specifically, 39\% of cases and 29\% of controls had a first degree relative with breast cancer. Although a similar fraction of cases and controls had ever had a full-term birth, fewer cases than controls had 3 or more full-term births. Among cases, the majority of tumors were of ductal histology (67\%) and luminal subtype (91\%).

We examined variation in the risk of breast cancer associated with 233 SNPs representing 31 genes in TLR or $\mathrm{NF} K \mathrm{~B}$ pathways. After correcting for multiple comparisons using the minP permutation test, variation in MAP3K1, MMP9, TANK, and TLR9 was found to be significant at the gene level (Table 2). Results from non-significant genes are presented in Additional file 1: Table S1. The single SNP we assayed in the region surrounding $M A P 3 K 1$, rs889312, was associated with breast cancer risk (OR 1.24, 95\% CI 1.06-1.44). In MMP9 we examined two coding SNPs and one intronic SNP. There 
Table 1 Selected characteristics of breast cancer cases and controls

\begin{tabular}{|c|c|c|c|c|}
\hline & \multicolumn{2}{|c|}{ Controls $(n=807)$} & \multicolumn{2}{|c|}{ Cases $(n=845)$} \\
\hline & $\mathrm{n}$ & $\%$ & $\mathrm{n}$ & $\%$ \\
\hline \multicolumn{5}{|c|}{ Age at reference } \\
\hline $65-69$ & 253 & 31.4 & 264 & 31.2 \\
\hline 70-74 & 301 & 37.3 & 329 & 38.9 \\
\hline $75-79$ & 253 & 31.4 & 252 & 29.8 \\
\hline \multicolumn{5}{|l|}{ Education } \\
\hline$<\mathrm{HS}$ & 108 & 13.4 & 103 & 12.2 \\
\hline HS grad & 325 & 40.3 & 332 & 39.3 \\
\hline Some college & 232 & 28.7 & 275 & 32.5 \\
\hline College grad+ & 142 & 17.6 & 135 & 16.0 \\
\hline \multicolumn{5}{|c|}{ Body mass index at reference } \\
\hline$<18.5$ & 14 & 1.8 & 14 & 1.7 \\
\hline $18.5-24.9$ & 322 & 41.2 & 293 & 35.6 \\
\hline $25-29.9$ & 244 & 31.2 & 290 & 35.2 \\
\hline $30+$ & 202 & 25.8 & 226 & 27.5 \\
\hline \multicolumn{5}{|c|}{ Number of full-term births } \\
\hline Nulliparous & 73 & 9.0 & 76 & 9.0 \\
\hline 1 & 55 & 6.8 & 79 & 9.3 \\
\hline 2 & 161 & 20.0 & 222 & 26.3 \\
\hline 3 & 221 & 27.4 & 216 & 25.6 \\
\hline $4+$ & 297 & 36.8 & 252 & 29.8 \\
\hline \multicolumn{5}{|c|}{ Age at menopause } \\
\hline$<45$ & 233 & 28.9 & 211 & 25.1 \\
\hline $45-49$ & 211 & 26.1 & 239 & 28.4 \\
\hline $50-54$ & 241 & 29.9 & 260 & 30.9 \\
\hline $55+$ & 122 & 15.1 & 131 & 15.6 \\
\hline \multicolumn{5}{|c|}{ Family history of breast cancer } \\
\hline None & 236 & 53.6 & 190 & 40.0 \\
\hline 1st degree & 129 & 29.3 & 184 & 38.7 \\
\hline 2nd degree & 75 & 17.0 & 101 & 21.3 \\
\hline \multicolumn{5}{|l|}{ Histology } \\
\hline Ductal & & & 565 & 66.9 \\
\hline Lobular & & & 105 & 12.4 \\
\hline Ductal/lobular & & & 70 & 8.3 \\
\hline Other & & & 105 & 12.4 \\
\hline \multicolumn{5}{|l|}{ ER/PR status } \\
\hline ER- PR- & & & 73 & 8.9 \\
\hline ER+ PR- & & & 80 & 9.8 \\
\hline ER- PR+ & & & 7 & 0.9 \\
\hline ER+ PR+ & & & 657 & 80.4 \\
\hline
\end{tabular}

was evidence that one of the coding SNPs, rs17576 (Q279R), was associated with an increased risk of breast cancer (OR 1.21, 95\% CI 1.04-1.40). Among controls, this
SNP was not found to be in high LD with the other two SNPs we examined in $M M P 9$ (all pairwise $\mathrm{r}^{2} \leq 0.50$ ). Of the six SNPs we examined in TANK, two were significantly associated with a $20 \%$ decreased risk of breast cancer: rs17705608 located in the flanking $5^{\prime}$ UTR and rs7309 located in the 3' UTR. These SNPs were in moderate LD among controls $\left(\mathrm{r}^{2}=0.67\right)$ and had identical relative risk estimates ( $\mathrm{rs} 17705608$ OR 0.83, 95\% CI 0.72-0.96; rs7309 OR 0.83, 95\% CI 0.73-0.95). The four other intronic SNPs did not show evidence of affecting breast cancer risk and were not in LD with any other SNPs in this region (all pairwise $r^{2} \leq 0.50$ ). Of the two SNPs we examined in TLR9, only the synonymous coding SNP rs352140 (P545P) was associated with breast cancer risk (OR 0.85, 95\% CI 0.74-0.97).

The results for these four genes were almost identical when analyses were confined to cases with ductal and luminal subtypes respectively (Table 3 ). For most SNPs, the magnitude of risk associated with each subtype was the same as with the overall risk of breast cancer. Further, only TLR9 was not significant at the gene level for either ductal or luminal subtypes $(\min P \quad P=0.14$ and 0.09 , respectively).

As an exploratory pathway analysis, we used the GRASS algorithm to examine genes in the KEGG "Tolllike receptor signaling pathway" (Figure 1). The first pathway we examined, which included TLR3, TLR4, TLR7, TLR9, TIRAP, TICAM1, TICAM2, TOLLIP, IRAK4, TRAF3, TRAF6, MAP3K7, IRF3, and IKBKE, was not significant after performing a permutation test $(P=0.24)$. Likewise, after permutation testing the second pathway we examined, which included these same genes in addition to NFKB1, NFKB2, RELA, and RELB, was not significant $(P=0.28)$.

We attempted to validate significant findings by assessing the risk of breast cancer associated with SNPs from our Seattle study using data from the CGEMS GWAS repository. Most SNPs found to be significant in our data were not found to be significant in the CGEMS data (Table 4). Only rs889312 from the region near MAP3K1 was replicated, and without correction for multiple comparisons $(P=0.04$ in CGEMS), with the suggestion of a slight increased risk of breast cancer (OR $1.15,95 \%$ CI 1.01-1.30). Although the associations with breast cancer were of similar magnitude and direction for most SNPs when comparing the two datasets, the risk of breast cancer associated with rs352140 in TLR9 was in the opposite direction (OR 1.06, 95\% CI 0.941.19) from that found in our data (OR $0.85,95 \%$ CI 0.74-0.97).

\section{Discussion}

We found that the risk of breast cancer was associated with genetic variation in four genes in either TLR or 
Table 2 Risk of breast cancer associated with SNPs in TLR or NFKB pathway genes

\begin{tabular}{|c|c|c|c|c|c|c|c|c|c|c|c|c|c|c|}
\hline \multirow[t]{2}{*}{ Function } & & \multirow[t]{2}{*}{$\begin{array}{l}\text { Maj/Min } \\
\text { Allele }\end{array}$} & \multicolumn{3}{|c|}{$\begin{array}{l}\text { Controls } \\
(n=807)\end{array}$} & \multicolumn{3}{|c|}{$\begin{array}{c}\text { Cases } \\
(n=845)\end{array}$} & \multirow[t]{2}{*}{ OR } & \multicolumn{2}{|c|}{$95 \% \mathrm{Cl}$} & \multirow[t]{2}{*}{$p$} & \multirow[t]{2}{*}{$\begin{array}{c}\text { SNP } \\
\text { perm } \mathrm{p}\end{array}$} & \multirow{2}{*}{$\begin{array}{c}\text { Gene } \\
\text { wide } \\
p\end{array}$} \\
\hline & & & 0 & 1 & 2 & 0 & 1 & 2 & & & & & & \\
\hline $\begin{array}{l}\text { MAP3K1 (chr 5: } 56146657 \text { - } \\
\text { 56227736) }\end{array}$ & & & & & & & & & & & & & & 0.006 \\
\hline rs889312 & Intergenic & $\mathrm{A} / \mathrm{C}$ & 434 & 318 & 49 & 417 & 337 & 86 & 1.24 & 1.06 & 1.44 & 0.006 & 0.006 & \\
\hline $\begin{array}{l}\text { MMP9 (chr 20: } 44070954 \text { - } \\
44078607 \text { ) }\end{array}$ & & & & & & & & & & & & & & 0.03 \\
\hline rs17576 & Coding: Q279R & $A / G$ & 366 & 357 & 78 & 338 & 393 & 106 & 1.21 & 1.04 & 1.40 & 0.01 & 0.03 & \\
\hline rs2274756 & $\begin{array}{l}\text { Coding: R668Q, } \\
\text { R668P }\end{array}$ & $\mathrm{G} / \mathrm{A}$ & 611 & 178 & 12 & 619 & 204 & 17 & 1.14 & 0.94 & 1.40 & 0.19 & - & \\
\hline rs3918262 & Intron & $A / G$ & 518 & 246 & 31 & 507 & 282 & 43 & 1.18 & 1.00 & 1.40 & 0.05 & 0.11 & \\
\hline $\begin{array}{l}\text { TANK (chr 2: } 161701712 \text { - } \\
\text { 161800928) }\end{array}$ & & & & & & & & & & & & & & 0.04 \\
\hline rs17705608 & Flanking 5' UTR & $A / G$ & 263 & 404 & 134 & 321 & 406 & 113 & 0.83 & 0.72 & 0.96 & 0.01 & 0.05 & \\
\hline rs7568498 & Intron & $\mathrm{A} / \mathrm{C}$ & 558 & 208 & 35 & 569 & 244 & 27 & 1.03 & 0.86 & 1.22 & 0.78 & - & \\
\hline rs1921310 & Intron & $A / G$ & 449 & 303 & 49 & 504 & 300 & 36 & 0.85 & 0.72 & 1.00 & 0.05 & 0.17 & \\
\hline rs1267074 & Intron & T/A & 397 & 310 & 94 & 382 & 373 & 84 & 1.05 & 0.91 & 1.22 & 0.48 & - & \\
\hline rs1267034 & Intron & $\mathrm{A} / \mathrm{G}$ & 623 & 159 & 19 & 631 & 191 & 18 & 1.11 & 0.91 & 1.35 & 0.31 & - & \\
\hline rs7309 & 3' UTR & $A / G$ & 196 & 392 & 212 & 240 & 421 & 179 & 0.83 & 0.73 & 0.95 & 0.008 & 0.04 & \\
\hline $\begin{array}{l}\text { TLR9 (chr 3: } 52230138 \text { - } \\
\text { 52235219) }\end{array}$ & & & & & & & & & & & & & & 0.03 \\
\hline rs352140 & Coding: P545P & $A / G$ & 219 & 391 & 191 & 267 & 406 & 167 & 0.85 & 0.74 & 0.97 & 0.02 & 0.03 & \\
\hline rs187084 & Flanking $5^{\prime}$ UTR & $A / G$ & 302 & 362 & 137 & 290 & 381 & 169 & 1.13 & 0.98 & 1.29 & 0.08 & 0.08 & \\
\hline
\end{tabular}

${ }^{a}$ All models are log-additive and adjusted for continuous linear age at reference.

bermutation p-values that are not significant according to the Holm multiple test procedure [38] are not presented.

Table 3 Risk of ductal and luminal breast cancer associated with SNPs in TLR or NFKB pathway genes

\begin{tabular}{|c|c|c|c|c|c|c|c|c|c|c|c|c|c|c|c|c|c|c|}
\hline \multirow{3}{*}{ MAP3K1 } & \multirow[t]{2}{*}{$\begin{array}{l}\text { Maj/Min } \\
\text { Allele }\end{array}$} & \multicolumn{3}{|c|}{$\begin{array}{l}\text { Controls } \\
(n=807)\end{array}$} & \multicolumn{3}{|c|}{$\begin{array}{c}\text { Ductal } \\
(n=565)\end{array}$} & \multirow[t]{2}{*}{ OR } & \multirow{2}{*}{\multicolumn{2}{|c|}{$95 \% \mathrm{Cl}$}} & \multirow{2}{*}{$\begin{array}{c}\text { Gene } \\
\text { wide } \\
P\end{array}$} & \multicolumn{3}{|c|}{$\begin{array}{l}\text { Luminal } \\
(n=744)\end{array}$} & \multirow[t]{2}{*}{ OR } & \multicolumn{2}{|c|}{$95 \% \mathrm{Cl}$} & \multirow{2}{*}{$\begin{array}{c}\text { Gene } \\
\text { wide } \\
P\end{array}$} \\
\hline & & 0 & 1 & 2 & 0 & 1 & 2 & & & & & 0 & 1 & 2 & & & & \\
\hline & & & & & & & & & & & 0.01 & & & & & & & 0.003 \\
\hline rs889312 & $\mathrm{A} / \mathrm{C}$ & 434 & 318 & 49 & 281 & 220 & 60 & 1.24 & 1.04 & 1.46 & & 361 & 301 & 77 & 1.27 & 1.08 & 1.48 & \\
\hline MMP9 & & & & & & & & & & & 0.02 & & & & & & & 0.02 \\
\hline rs17576 & $\mathrm{A} / \mathrm{G}$ & 366 & 357 & 78 & 216 & 276 & 67 & 1.24 & 1.05 & 1.46 & & 296 & 340 & 100 & 1.23 & 1.06 & 1.43 & \\
\hline rs 2274756 & $\mathrm{G} / \mathrm{A}$ & 611 & 178 & 12 & 424 & 129 & 8 & 1.03 & 0.82 & 1.29 & & 541 & 183 & 15 & 1.17 & 0.95 & 1.44 & \\
\hline rs3918262 & $A / G$ & 518 & 246 & 31 & 327 & 195 & 35 & 1.29 & 1.08 & 1.56 & & 444 & 248 & 40 & 1.20 & 1.01 & 1.43 & \\
\hline TANK & & & & & & & & & & & 0.002 & & & & & & & 0.004 \\
\hline rs17705608 & $\mathrm{A} / \mathrm{G}$ & 263 & 404 & 134 & 230 & 256 & 75 & 0.78 & 0.67 & 0.92 & & 284 & 358 & 97 & 0.82 & 0.71 & 0.95 & \\
\hline rs7568498 & $\mathrm{A} / \mathrm{C}$ & 558 & 208 & 35 & 385 & 161 & 15 & 0.98 & 0.80 & 1.19 & & 495 & 223 & 21 & 1.04 & 0.87 & 1.25 & \\
\hline rs1921310 & $\mathrm{A} / \mathrm{G}$ & 449 & 303 & 49 & 347 & 191 & 23 & 0.80 & 0.67 & 0.96 & & 446 & 261 & 32 & 0.84 & 0.71 & 1.00 & \\
\hline rs1267074 & T/A & 397 & 310 & 94 & 251 & 253 & 56 & 1.07 & 0.91 & 1.26 & & 326 & 336 & 76 & 1.09 & 0.94 & 1.27 & \\
\hline rs1267034 & $\mathrm{A} / \mathrm{G}$ & 623 & 159 & 19 & 412 & 137 & 12 & 1.19 & 0.95 & 1.48 & & 546 & 176 & 17 & 1.17 & 0.96 & 1.44 & \\
\hline rs7309 & $A / G$ & 196 & 392 & 212 & 179 & 264 & 118 & 0.78 & 0.67 & 0.91 & & 216 & 375 & 148 & 0.80 & 0.69 & 0.92 & \\
\hline TLR9 & & & & & & & & & & & 0.14 & & & & & & & 0.09 \\
\hline rs352140 & $\mathrm{A} / \mathrm{G}$ & 219 & 391 & 191 & 180 & 268 & 113 & 0.85 & 0.73 & 0.99 & & 234 & 359 & 146 & 0.85 & 0.74 & 0.98 & \\
\hline rs187084 & $\mathrm{A} / \mathrm{G}$ & 302 & 362 & 137 & 190 & 254 & 117 & 1.16 & 1.00 & 1.34 & & 254 & 337 & 148 & 1.13 & 0.98 & 1.30 & \\
\hline
\end{tabular}

${ }^{\mathrm{a}}$ All models are log-additive and adjusted for continuous linear age at reference. 


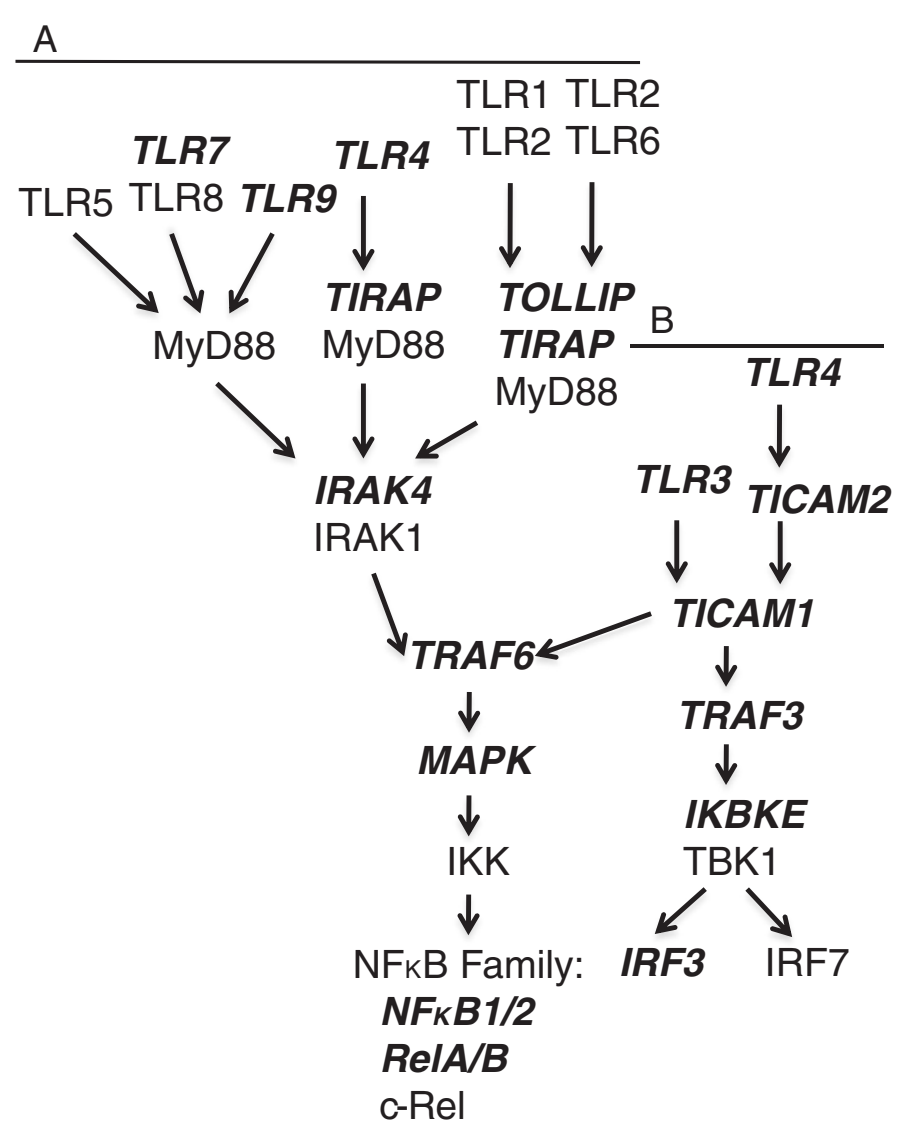

Figure 1 Toll-like Receptor (TLR) Signaling Pathways. Classical TLR signaling pathways that result in NFkB activation are either MyD88dependent (A) or MyD88-independent (B). In MyD88-dependent pathways TLR signaling occurs through the IRAK4/IRAK1 complex, while in MyD88-independent pathways TLRs signal through TICAM1. TRAF6 then signals to the IKK complex through MAP3K7, which finally leads to NFKB activation. MyD88-independent signaling pathways can also result in the activation of IRF3 or IRF7. Genes assayed by this study are bolded and italicized. This figure was adapted from the KEGG "Toll-like receptor signaling pathway" (http://www.genome.jp/kegg/pathway/hsa/hsa04620. html).

Table 4 Risk of breast cancer associated with SNPs in the CGEMS GWAS data

\begin{tabular}{|c|c|c|c|c|c|c|c|c|c|c|c|}
\hline & \multirow{2}{*}{$\begin{array}{l}\text { Maj/Min } \\
\text { Allele }\end{array}$} & \multicolumn{3}{|c|}{ Controls $(n=1142)$} & \multicolumn{3}{|c|}{ Cases $(n=1145)$} & \multirow[t]{2}{*}{$\mathrm{OR}^{\mathrm{a}}$} & \multicolumn{2}{|c|}{$95 \% \mathrm{Cl}$} & \multirow[t]{2}{*}{$P$} \\
\hline & & 0 & 1 & 2 & 0 & 1 & 2 & & & & \\
\hline \multicolumn{12}{|l|}{ MAP3K1 } \\
\hline rs889312 & $\mathrm{A} / \mathrm{C}$ & 607 & 447 & 88 & 552 & 499 & 94 & 1.15 & 1.01 & 1.30 & 0.04 \\
\hline \multicolumn{12}{|l|}{ MMP9 } \\
\hline rs17576 & $A / G$ & 464 & 542 & 136 & 452 & 541 & 152 & 1.05 & 0.93 & 1.19 & 0.39 \\
\hline \multicolumn{12}{|l|}{ TANK } \\
\hline rs17705608 & $A / G$ & 412 & 535 & 195 & 442 & 538 & 165 & 0.90 & 0.80 & 1.01 & 0.07 \\
\hline rs7309 & $\mathrm{G} / \mathrm{A}$ & 303 & 541 & 286 & 312 & 570 & 241 & 0.91 & 0.81 & 1.02 & 0.10 \\
\hline \multicolumn{12}{|l|}{ TLR9 } \\
\hline rs352140 & $\mathrm{T} / \mathrm{C}$ & 356 & 560 & 226 & 337 & 572 & 236 & 1.06 & 0.94 & 1.19 & 0.36 \\
\hline
\end{tabular}

${ }^{a}$ All models are log-additive and adjusted for age in 5 year groups. 
NFKB pathways: MAP3K1, MMP9, TANK, and TLR9. Results were unchanged within cases with ductal or luminal subtypes. However, after replicating our results using the CGEMS GWAS data, only rs889312 from the region near MAP3K1 was associated with breast cancer risk.

MAP3K1 is a key player in TLR signaling pathways and produces downstream signaling for the NFkB pathway as well as the ERK and JNK kinase pathways $[39,40]$. Our finding for rs889312 is consistent with previous results, as variants near MAP3K1 have been found to be significant in three prior GWAS studies [31,32,41]. Easton et al. found rs889312 to be significantly associated with breast cancer risk in 4,398 breast cancer cases and 4,316 controls [31]. They confirmed this finding in 21,860 cases and 22,578 controls using data from the Breast Cancer Association Consortium (BCAC) GWAS, which combined 22 case-control studies. Further, the magnitude of risk in the Easton et al. study was comparable to that found in our study population for rs 889312 (OR 1.13, 95\% CI 1.10-1.16). In a more recent GWAS, Turnbull et al. also found that rs889312 was associated with an increased risk of breast cancer among 12,576 cases and 12,223 controls (OR 1.22, 95\% CI 1.14-1.30) [32]. In the CGEMS GWAS, they did not directly assess rs889312 but they found that rs16886165 significantly affected the risk of breast cancer after combining 5,440 cases and 5,283 controls [41]. After we imputed rs889312 in the CGEMS data, we found it was in moderate LD with $\mathrm{rs} 16886165\left(\mathrm{r}^{2}=0.68\right)$. A candidate gene study, which used 1,267 Dutch breast cancer cases and 20,973 controls from the BCAC GWAS, did not find rs889312 to significantly affect breast cancer risk (OR 1.03, $P=0.72$ ), though they did find that this SNP was associated with lymph-node status $(P=0.04)$ [42]. However, as the population used in this Dutch study was a subset of the BCAC GWAS, it is important to note that their results correlate with those from the BCAC GWAS.

We also investigated variation in $M M P 9$, as MMPs influence cancer progression and contribute to tumor angiogenesis, growth, and metastasis by degrading the extracellular matrix and activating growth factors [43]. $M M P 9$ expression is regulated by NFKB [44], and in one study was shown to be correlated with NFKB activation in patients with squamous cell carcinoma of the uterine cervix [45]. Although no GWAS studies have found SNPs in $M M P 9$ to affect breast cancer risk, many prior studies have published results that support an association between $M M P 9$ and breast cancer risk. Two previous analyses of expression found MMP9 plasma concentrations were greater in breast cancer cases compared to controls [46,47]. In a Polish study of 270 breast cancer cases and 300 controls, Przybylowska et al. found increased levels of MMP9 in tumor samples compared to normal breast tissue and an increased risk of breast cancer associated with the $\mathrm{T}$ allele for rs3918242 in MMP9 (OR 2.6, 95\% CI 1.3-4.9) [48]. In a candidate gene study of 959 cases and 952 controls from Sweden, Lei et al. found a non-significant increased risk of breast cancer associated with TT homozygotes for rs3918242 (OR 1.88, 95\% CI 0.97-3.63) [49]. However, findings from two prior meta-analyses of case-control studies (one which used 15,328 cases and 15,253 controls) showed no association between rs3918242 and breast cancer risk [50,51]. Our study is the only one to date to find an association between the coding SNP rs17576 in $M M P 9$ and breast cancer risk.

Another NFKB gene we investigated was TANK (also known as TRAF2), which is a critical upstream component in the NFKB activation pathway and therefore could be a factor that relates to inflammation as well as cancer development and progression [12,13,52,53]. Although two SNPs in TANK (rs17705608 and rs7309) were significantly associated with breast cancer risk in our study sample, interestingly no prior GWAS or candidate gene studies have reported on genetic variants in TANK affecting the risk of breast cancer. In the CGEMS GWAS data, neither of these SNPs was strongly associated with breast cancer risk (rs17705608 OR 0.90, 95\% CI 0.801.01; rs7309 OR 0.91, 95\% CI 0.81-1.02).

As TLR pathways are central in tissue repair and regeneration $[19,54,55]$, we investigated several TLRs including TLR9. No GWAS studies to date have found that breast cancer risk is influenced by variants in TLR9. We found that rs352140 in TLR9 was associated with breast cancer risk (OR 0.85, 95\% CI 0.74-0.97). Although this SNP is synonymous and does not alter the protein sequence, it could affect the protein via perturbations in mRNA splicing and stability, altered structure of mRNA, and (though less well-established) effects on protein folding [56]. Our result for rs352140 was in contrast to a small Croatian study that found no association in 130 breast cancer cases and 101 controls (and which may have been underpowered to detect this association) [57]. However, expression studies have found breast cancer patients to have high levels of TLR9 [21,58,59]. Berger et al found that women with breast cancer had higher circulating levels of TLR9 compared to controls, and that TLR9 mRNA expression was correlated with NFkB activity in breast cancer patients [58]. Therefore, future studies should continue to assess the relationship between polymorphisms in TLR 9 and breast cancer risk.

In exploratory pathway analyses we did not observe an association between TLR-NFKB related genes and breast cancer risk. Although the results from these exploratory pathway analyses do not suggest that breast cancer risk is affected by combined variation in the genes that we 
examined from the KEGG "Toll-like receptor signaling pathway", this study may have been limited to detect such an association given our sample size and the absence of some key genes within this pathway (such as MyD88, TLR1, and TLR2). Given the biologic plausibility that genes within this pathway could affect cancer development and progression, it would be of interest for further studies to include pathway analyses, particularly those that have larger sample sizes, improved coverage of SNP variation, and other sources of variation such as epigenetic influences.

Although this study suggested variation in four genes, MAP3K1, MMP9, TANK, and TLR9, may affect the risk of breast cancer, previous studies have observed associations for other genes in TLR or NFKB pathways. For example, prior studies have identified polymorphisms in TLR4 (rs4986790) [60] and TNF (rs361525 and rs1800629) [61-63] that affect breast cancer risk. A prior study, that included a subset of the participants in this study, found breast cancer risk was associated with a UTR 5 ' flanking SNP (rs2009658) in lymphotoxin alpha (LTA) (OR 1.2, 95\% CI 1.1-1.4) as well as a nonsynonomous coding SNP (rs767455) in the TNF receptor TNFRSF1A (OR 1.2, 95\% CI 1.1-1.4) [64].

There were some limitations to this study that should be considered in the interpretation of our results. Our sample size may not have been sufficient to capture the true level of association between genetic variants with low frequency and breast cancer risk. Also, the assays we used may have misclassified or failed to detect variation in the genes we analyzed. However, misclassification is not likely a problem as the repeat samples were highly concordant. There could also be missed variation due to incomplete coverage of genes or due to our limited number of SNPs. It is also possible that we did not characterize important variation in these genes, since particular variants, such as deletions, variants in repeat regions, and copy number variants, were not detectable on the platforms we used for genotyping. Another limitation is that we did not genotype variants for every gene in TLR or NFאB related pathways. Therefore, potentially important associations between key genes in these pathways may have been missed. In addition, although we attempted to control for potential population stratification by restricting our sample to white women using principal components analysis, it is possible our analyses were subject to uncontrolled confounding from admixture.

There were a number of strengths to this study. For one, our well-characterized study population is representative of post-menopausal women at risk of breast cancer in the Seattle metropolitan area. Also the populationbased controls are representative of those at risk of disease. Further, our study sample is consistent with other populations that have been used to analyze breast cancer risk, raising the likelihood that associations from this study are generalizable to similar populations. Another strength of this study was our use of a tagSNP approach that maximized genetic coverage. Finally, by using data from the CGEMS GWAS to validate our findings we were able to draw stronger conclusions regarding the association between genetic variants in TLR or NFKB pathways and breast cancer risk.

\section{Conclusions}

Overall, the results of this study do not suggest a strong association between breast cancer risk and the SNPs in the candidate genes we analyzed in TLR or NFkB pathways. Despite our findings, there is a compelling biologic rationale for an association between genetic variation in these pathways and breast cancer risk. Given the few suggestive associations in our data and results from prior studies that implicate plausible associations between breast cancer risk and genes in TLR or NFKB pathways, further studies are warranted that examine these effects.

\section{Additional file}

Additional file 1: Table S1. Risk of Breast Cancer Associated with SNPS in Non-significant TLR or NFKB Pathway Genes.

\section{Competing interests}

The authors declare that they have no competing interests.

\section{Authors' contributions}

MMM and KEM provided the concept of the study as well as funding. MM and EWP provided laboratory methodology and expertise in evaluating the assay results. The analysis plan was developed by KEM, LGJ, AJR, and MMM under the direction of BM. Data analysis was performed by AJR and LGJ. AJR conducted the literature review and prepared the manuscript, including the Background, Materials and Methods, Results, Discussion, and Conclusions sections. All authors contributed substantially to revisions toward the final manuscript. All authors read and approved the final manuscript.

\section{Acknowledgements}

We would like to acknowledge the support this study received from the National Cancer Institute grant R01 CA116786 and the National Institute of Health grants that supported the PACE parent study (National Cancer Institiute, R01 CA72787).

\section{Author details}

${ }^{1}$ Program in Epidemiology, Fred Hutchinson Cancer Research Center, 1100 Fairview Avenue North, Seattle, WA 98109, USA. ${ }^{2}$ Program in Immunogenetics, Fred Hutchinson Cancer Research Center, 1100 Fairview Avenue North, Seattle, WA 98109, USA. ${ }^{3}$ Department of Epidemiology, University of Washington, Health Sciences Building, NE Pacific Street, Seattle, WA 98195, USA. ${ }^{4}$ Department of Biostatistics, University of Washington, Health Sciences Building, NE Pacific Street, Seattle, WA 98195, USA. ${ }^{5}$ Fred Hutchinson Cancer Research Center, 1100 Fairview Ave N, Mail Stop M4C308, Seattle, WA 98109, USA.

Received: 7 November 2012 Accepted: 25 April 2013

Published: 1 May 2013

\section{References}

1. Mantovani A, Allavena P, Sica A, Balkwill F: Cancer-related inflammation. Nature 2008, 454:436-444. 
2. Mantovani A, Garlanda C, Allavena P: Molecular pathways and targets in cancer-related inflammation. Ann Med 2010, 42:161-170.

3. Colotta F, Allavena P, Sica A, Garlanda C, Mantovani A: Cancer-related inflammation, the seventh hallmark of cancer: links to genetic instability. Carcinogenesis 2009, 30:1073-1081.

4. Coussens LM, Werb Z: Inflammation and cancer. Nature 2002, 420:860-867.

5. Balkwill F, Charles KA, Mantovani A: Smoldering and polarized inflammation in the initiation and promotion of malignant disease. Cancer Cell 2005, 7:211-217.

6. Mantovani A: Cancer: inflaming metastasis. Nature 2009, 457:36-37.

7. Hanahan D, Weinberg RA: Hallmarks of cancer: the next generation. Cell 2011, 144:646-674.

8. Ben-Neriah Y, Karin M: Inflammation meets cancer, with NF-kappaB as the matchmaker. Nat Immunol 2011, 12:715-723.

9. Didonato JA, Mercurio F, Karin M: NF-kappaB and the link between inflammation and cancer. Immunol Rev 2012, 246:379-400.

10. Li Q, Verma IM: NF-kappaB regulation in the immune system. Nat Rev Immunol 2002, 2:725-734.

11. Xiao C, Ghosh S: NF-kappaB, an evolutionarily conserved mediator of immune and inflammatory responses. Adv Exp Med Biol 2005, 560:41-45.

12. Hayden MS, West AP, Ghosh S: NF-kappaB and the immune response. Oncogene 2006, 25:6758-6780.

13. Viatour P, Merville MP, Bours V, Chariot A: Phosphorylation of NF-kappaB and IkappaB proteins: implications in cancer and inflammation. Trends Biochem Sci 2005, 30:43-52

14. Dolcet $X$, Llobet D, Pallares J, Matias-Guiu X: NF-kB in development and progression of human cancer. Virchows Arch 2005, 446:475-482.

15. Sun SC, Xiao G: Deregulation of NF-kappaB and its upstream kinases in cancer. Cancer Metastasis Rev 2003, 22:405-422.

16. Karin M, Cao Y, Greten FR, Li ZW: NF-kappaB in cancer: from innocent bystander to major culprit. Nat Rev Cancer 2002, 2:301-310.

17. Karin M: Nuclear factor-kappaB in cancer development and progression. Nature 2006, 441:431-436.

18. Wood LD, Parsons DW, Jones S, Lin J, Sjoblom T, Leary RJ, et al: The genomic landscapes of human breast and colorectal cancers. Science 2007, 318:1108-1113.

19. Rakoff-Nahoum S, Medzhitov R: Toll-like receptors and cancer. Nat Rev Cancer 2009, 9:57-63.

20. Li X, Jiang S, Tapping Rl: Toll-like receptor signaling in cell proliferation and survival. Cytokine 2010, 49:1-9.

21. Merrell MA, Ilvesaro JM, Lehtonen N, Sorsa T, Gehrs B, Rosenthal E, et al: Toll-like receptor 9 agonists promote cellular invasion by increasing matrix metalloproteinase activity. Mol Cancer Res 2006, 4:437-447.

22. Yang $H$, Zhou $H$, Feng $P$, Zhou $X$, Wen $H$, Xie $X$, et al: Reduced expression of Toll-like receptor 4 inhibits human breast cancer cells proliferation and inflammatory cytokines secretion. J Exp Clin Cancer Res 2010, 29:92.

23. Xie $W$, Wang $Y$, Huang $Y$, Yang $H$, Wang J, Hu Z: Toll-like receptor 2 mediates invasion via activating NF-kappaB in MDA-MB-231 breast cancer cells. Biochem Biophys Res Commun 2009, 379:1027-1032.

24. Karban AS, Okazaki T, Panhuysen Cl, Gallegos T, Potter JJ, Bailey-Wilson JE, et al: Functional annotation of a novel NFKB1 promoter polymorphism that increases risk for ulcerative colitis. Hum Mol Genet 2004, 13:35-45.

25. Wilson AG, Symons JA, McDowell TL, McDevitt HO, Duff GW: Effects of a polymorphism in the human tumor necrosis factor alpha promoter on transcriptional activation. Proc Natl Acad Sci U S A 1997, 94:3195-3199.

26. Kroeger KM, Carville KS, Abraham LJ: The -308 tumor necrosis factoralpha promoter polymorphism effects transcription. Mol Immunol 1997, 34:391-399.

27. Arbour NC, Lorenz E, Schutte BC, Zabner J, Kline JN, Jones M, et al: TLR4 mutations are associated with endotoxin hyporesponsiveness in humans. Nat Genet 2000, 25:187-191.

28. $\mathrm{Li} \mathrm{Cl}$, Malone KE, Porter PL, Weiss NS, Tang MT, Cushing-Haugen $\mathrm{KL}$, et al: Relationship between long durations and different regimens of hormone therapy and risk of breast cancer. JAMA 2003, 289:3254-3263.

29. Hankey BF, Ries LA, Edwards BK: The surveillance, epidemiology, and end results program: a national resource. Cancer Epidemiol Biomark Prev 1999 8:1117-1121.

30. Edlund CK, Lee WH, Li D, Van Den Berg DJ, Conti DV: Snagger: a userfriendly program for incorporating additional information for tagSNP selection. BMC Bioinforma 2008, 9:174.
31. Easton DF, Pooley KA, Dunning AM, Pharoah PD, Thompson D, Ballinger DG, et al: Genome-wide association study identifies novel breast cancer susceptibility loci. Nature 2007, 447:1087-1093.

32. Turnbull C, Ahmed S, Morrison J, Pernet D, Renwick A, Maranian M, et al: Genome-wide association study identifies five new breast cancer susceptibility loci. Nat Genet 2010, 42:504-507.

33. Price AL, Patterson NJ, Plenge RM, Weinblatt ME, Shadick NA, Reich D: Principal components analysis corrects for stratification in genome-wide association studies. Nat Genet 2006, 38:904-909.

34. Dudoit S, van der Laan MJ, Pollard KS: Multiple testing. Part I. Single-step procedures for control of general type I error rates. Stat Appl Genet Mol Biol 2004, 3:Article13.

35. Chen LS, Hutter CM, Potter JD, Liu Y, Prentice RL, Peters U, et al: Insights into colon cancer etiology via a regularized approach to gene set analysis of GWAS data. Am J Hum Genet 2010, 86:860-871.

36. Browning BL, Browning SR: A unified approach to genotype imputation and haplotype-phase inference for large data sets of trios and unrelated individuals. Am J Hum Genet 2009, 84:210-223.

37. Hunter DJ, Kraft P, Jacobs KB, Cox DG, Yeager M, Hankinson SE, et al: A genome-wide association study identifies alleles in FGFR2 associated with risk of sporadic postmenopausal breast cancer. Nat Genet 2007, 39:870-874.

38. Holm S: A simple sequentially rejective multiple test procedure. Scand J Stat 1979, 6:65-70.

39. Blander JM: Analysis of the TLR/NF-kappaB pathway in antigenpresenting cells in malignancies promoted by inflammation. Methods $\mathrm{Mol}$ Biol 2009, 512:99-117.

40. Kawai T, Akira S: Signaling to NF-kappaB by Toll-like receptors. Trends Mol Med 2007, 13:460-469.

41. Thomas G, Jacobs KB, Kraft P, Yeager M, Wacholder S, Cox DG, et al: A multistage genome-wide association study in breast cancer identifies two new risk alleles at 1p11.2 and 14q24.1 (RAD51L1). Nat Genet 2009, 41:579-584

42. Huijts PE, Vreeswijk MP, Kroeze-Jansema KH, Jacobi CE, Seynaeve C, KrolWarmerdam EM, et al: Clinical correlates of low-risk variants in FGFR2, TNRC9, MAP3K1, LSP1 and 8q24 in a Dutch cohort of incident breast cancer cases. Breast Cancer Res 2007, 9:R78.

43. Klein G, Vellenga E, Fraaije MW, Kamps WA, de Bont ES: The possible role of matrix metalloproteinase (MMP)-2 and MMP-9 in cancer, e.g. acute leukemia. Crit Rev Oncol Hematol 2004, 50:87-100.

44. Bond M, Fabunmi RP, Baker AH, Newby AC: Synergistic upregulation of metalloproteinase- 9 by growth factors and inflammatory cytokines: an absolute requirement for transcription factor NF-kappa B. FEBS Lett 1998, 435:29-34.

45. Gasparian AV, Fedorova MD, Kisselev FL: Regulation of matrix metalloproteinase- 9 transcription in squamous cell carcinoma of uterine cervix: the role of human papillomavirus gene E2 expression and activation of transcription factor NF-kappaB. Biochemistry (Mosc) 2007, 72:848-853

46. Somiari SB, Somiari RI, Heckman CM, Olsen CH, Jordan RM, Russell SJ, et al: Circulating MMP2 and MMP9 in breast cancer-potential role in classification of patients into low risk, high risk, benign disease and breast cancer categories. Int J Cancer 2006, 119:1403-1411.

47. Wu ZS, Wu Q, Yang JH, Wang HQ, Ding XD, Yang F, et al: Prognostic significance of MMP-9 and TIMP-1 serum and tissue expression in breast cancer. Int J Cancer 2008, 122:2050-2056.

48. Przybylowska K, Kluczna A, Zadrozny M, Krawczyk T, Kulig A, Rykala J, et al: Polymorphisms of the promoter regions of matrix metalloproteinases genes MMP-1 and MMP-9 in breast cancer. Breast Cancer Res Treat 2006, 95:65-72.

49. Lei H, Hemminki K, Altieri A, Johansson R, Enquist K, Hallmans G, et al: Promoter polymorphisms in matrix metalloproteinases and their inhibitors: few associations with breast cancer susceptibility and progression. Breast Cancer Res Treat 2007, 103:61-69.

50. McColgan P, Sharma P: Polymorphisms of matrix metalloproteinases 1, 2 3 and 9 and susceptibility to lung, breast and colorectal cancer in over 30,000 subjects. Int J Cancer 2009, 125:1473-1478.

51. Zhou P, Du LF, LV GQ, Yu XM, Gu YL, Li JP, et al: Current evidence on the relationship between four polymorphisms in the matrix metalloproteinases (MMP) gene and breast cancer risk: a meta-analysis. Breast Cancer Res Treat 2011, 127:813-818.

52. Inoue J, Gohda J, Akiyama T, Semba K: NF-kappaB activation in development and progression of cancer. Cancer Sci 2007, 98:268-274. 
53. Pomerantz $\mathrm{J}$, Baltimore D: NF-kappaB activation by a signaling complex containing TRAF2, TANK and TBK1, a novel IKK-related kinase. EMBO J 1999, 18:6694-6704.

54. Sato Y, Goto Y, Narita N, Hoon DS: Cancer cells expressing Toll-like receptors and the tumor microenvironment. Cancer Microenviron 2009, 2 (Suppl 1):205-214.

55. Chen R, Alvero AB, Silasi DA, Steffensen KD, Mor G: Cancers take their Tollthe function and regulation of Toll-like receptors in cancer cells. Oncogene 2008, 27:225-233.

56. Hunt R, Sauna ZE, Ambudkar SV, Gottesman MM, Kimchi-Sarfaty C: Silent (synonymous) SNPs: should we care about them? Methods Mol Biol 2009, 578:23-39.

57. Etokebe GE, Knezevic J, Petricevic B, Pavelic J, Vrbanec D, Dembic Z: Singlenucleotide polymorphisms in genes encoding toll-like receptor $-2,-3,-4$, and -9 in case-control study with breast cancer. Genet Test Mol Biomark 2009, 13:729-734.

58. Berger R, Fiegl H, Goebel G, Obexer P, Ausserlechner M, Doppler W, et al: Toll-like receptor 9 expression in breast and ovarian cancer is associated with poorly differentiated tumors. Cancer Sci 2010, 101:1059-1066.

59. Gonzalez-Reyes S, Marin L, Gonzalez L, Gonzalez LO, del Casar JM, Lamelas ML, et al: Study of TLR3, TLR4 and TLR9 in breast carcinomas and their association with metastasis. BMC Cancer 2010, 10:665.

60. Burton PR, Clayton DG, Cardon LR, Craddock N, Deloukas P, Duncanson A, et al: Association scan of 14,500 nonsynonymous SNPs in four diseases identifies autoimmunity variants. Nat Genet 2007, 39:1329-1337.

61. Gaudet MM, Egan KM, Lissowska J, Newcomb PA, Brinton LA, Titus-Ernstoff $L$, et al: Genetic variation in tumor necrosis factor and lymphotoxin-alpha (TNF-LTA) and breast cancer risk. Hum Genet 2007, 121:483-490.

62. Kohaar I, Tiwari P, Kumar R, Nasare V, Thakur N, Das BC, et al: Association of single nucleotide polymorphisms (SNPs) in TNF-LTA locus with breast cancer risk in Indian population. Breast Cancer Res Treat 2009, 114:347-355.

63. Fang F, Yao L, Yu XJ, Yu L, Wu Q, Yu L: TNFalpha -308 G/A polymorphism is associated with breast cancer risk: a meta-analysis involving 10,184 cases and 12,911 controls. Breast Cancer Res Treat 2010, 122:267-271.

64. Madeleine MM, Johnson LG, Malkki M, Resler AJ, Petersdorf EW, McKnight B, et al: Genetic variation in proinflammatory cytokines IL6, IL6R, TNFregion, and TNFRSF1A and risk of breast cancer. Breast Cancer Res Treat 2011, 129:887-899.

doi:10.1186/1471-2407-13-219

Cite this article as: Resler et al:: Genetic variation in TLR or NFkappaB pathways and the risk of breast cancer: a case-control study. BMC Cancer 2013 13:219.

\section{Submit your next manuscript to BioMed Central and take full advantage of:}

- Convenient online submission

- Thorough peer review

- No space constraints or color figure charges

- Immediate publication on acceptance

- Inclusion in PubMed, CAS, Scopus and Google Scholar

- Research which is freely available for redistribution 